\title{
A method for improving Centre for Environmental Studies (CML) characterisation factors for metal (eco)toxicity - the case of zinc gutters and downpipes
}

\author{
Tom N. Ligthart • Ruud H. Jongbloed • \\ Jacqueline E. Tamis
}

Received: 22 July 2009 /Revised: 3 May 2010 /Accepted: 2 June 2010 / Published online: 25 June 2010

(C) The Author(s) 2010. This article is published with open access at Springerlink.com

\begin{abstract}
Background, aim and scope The environmental impact of building products made from heavy metals has been a topic of discussion for some years. This was fuelled by results of life cycle assessments (LCAs), where the emission of heavy metals strongly effected the results. An issue was that the characterisation factors of the Centre for Environmental Studies (CML) 2000 life cycle impact assessment (LCIA) methodology put too much emphasis on the impact of metal emissions. We adjusted $\mathrm{Zn}$ characterisation factors according to the most recent insights in the ecotoxicity of zinc and applied them in an LCA using zinc gutters and downpipes as an example.

Materials and methods The CML 2000 methodology was used to assess the environmental impact of the zinc products. To adjust the $\mathrm{Zn}$ characterisation factors, the uniform system for the evaluation of substances (USES)LCA model and the biotic ligand model were used.

Results and discussion The first correction was based on updating the effect values for zinc. This resulted in a reduction of the characterisation factors for zinc to $42 \%$ of their original values. Additional correcting for the bioavailability of zinc leads to final $\mathrm{Zn}$ characterisation factors for the freshwater aquatic ecotoxicity potential (FAETP), the marine aquatic ecotoxicity potential (MAETP) and the terrestrial ecotoxicity
\end{abstract}

T. N. Ligthart $(\bowtie)$

TNO Built Environment and Geosciences,

Department of Environment, Health and Safety,

Utrecht, The Netherlands

e-mail: tom.ligthart@tno.nl

R. H. Jongbloed $\cdot$ J. E. Tamis

Department of Environment,

Institute for Marine Resources and Ecosystem Studies (IMARES),

Den Helder, The Netherlands

e-mail: Ruud.Jongbloed@wur.nl

e-mail: Jacqueline.Tamis@wur.nl potential (TETP) of $25 \%, 42 \%$ and $0.006 \%$, respectively, of the original values. The CML 2000 LCIA methodology is based on the predicted no-effect concentration (PNEC) of a substance. PNEC is not value-free as political considerations are used to decide on it. Using a more robust toxicity measure as the hazardous concentration at which $50 \%$ of the species is affected (HC50) will provide value-free results. The production of standard high-grade zinc shows main contributions to six of the ten environmental impact categories. The recycling of zinc at the end of the life cycle shows beneficial effects for these same categories. Despite the reduction of the characterisation factor of $\mathrm{Zn}$, the runoff emissions of $\mathrm{Zn}$ are still dominant.

Conclusions and recommendations To improve LCA characterisation factors for ecotoxicity in the CML 2000 methodology, it is recommended to use either the geometric mean of the effect data or the HC50. The HC50 should be based upon the EC50 values from chronic ecotoxicity tests. It is proposed to include the bioavailability of metals in LCA in three steps: (1) separate soluble fraction, (2) separate dissolved fraction and (3) separate bioavailable fraction. The issue of essentiality could not be resolved in this study. However, this could be accounted for by leaving out the fraction of the emission below the maximum permissible admission.

Keywords Bioavailability . Characterisation factor. Emissions · HC50 (hazardous concentration affecting 50\% of the species) - Impact assessment .

PNEC (predicted no-effect concentration) - Zinc

$\begin{array}{ll}\text { Abbreviations } \\ \text { ADP } & \text { Abiotic Depletion Potential } \\ \text { AP } & \text { Acidification Potential } \\ \text { BLM } & \text { Biotic Ligand Model }\end{array}$


CML Centre for Environmental Studies, Leiden, Netherlands

EP Eutrophication Potential

FAETP Freshwater Aquatic EcoToxicity Potential

GWP Global Warming Potential

HC50 Hazardous Concentration at which $50 \%$ of the species is affected

HTP Human Toxicity Potential

$K_{\mathrm{p}} \quad$ Partition coefficient

LCA Life Cycle Assessment

LCI Life Cycle Inventory

LCIA Life Cycle Impact Assessment

MAETP Marine Aquatic EcoToxicity Potential

MPA Maximum Permissible Addition

MPC Maximum Permissible Concentration

MSWI Municipal Solid Waste Incinerator

NOEC No Observed Effect Concentration

ODP Ozone Depletion Potential

PNEC Predicted No-Effect Concentration

POCP Photochemical Ozone Creation Potential

RAR Risk Assessment Report

SHG Special High Grade

TETP Terrestrial EcoToxicity Potential

USES Uniform System for the Evaluation of Substances

\section{Background, aim and scope}

The method of environmental life cycle assessment (LCA) is seen as a suitable instrument for the evaluation of the environmental impacts of a product or an activity through its entire life cycle (Guinée et al. 2001). LCA is a systematic way to evaluate the environmental impacts of product systems or activities by following a 'cradle-tograve' approach. The product system consists of a set of activities (processes), all focused on the fulfillment of the required function. The LCA methodology is structured along a framework with four main steps: goal and scope definition, inventory, impact assessment and interpretation. Guidance for these steps is given in ISO guidelines 14040 and 14044 (ISO 2006a,b).

An issue that has become increasingly more important is the role of essential metals, zinc being one of them, in life cycle impact assessment (LCIA). It appears that the current LCIA practice overemphasises the contribution of these metals to the ecotoxicity-related impact categories. In 2004, a group of specialists on risk assessment and on LCIA published the 'Apeldoorn Declaration' in which the specific aspects of essential metals regarding LCIA were pinpointed and recommendations were given on how to deal with these metals in LCIA (Ligthart et al. 2004). This study follows up on some of these recommendations with the aim to improve
LCIA for essential metals, using zinc gutters and downpipes as a case study. The aspects addressed in this study are as follows.

1.1 Evaluation and update of current effect values for zinc

In the Centre for Environmental Studies (CML) 2000 baseline LCIA, characterisation factors are used to compare the ecotoxicity of substances. Characterisation factors are derived from ecotoxicological effect factors and fate data. An effect factor is based on a predicted no-effect concentration (PNEC) value and is used to express the relative toxicity of each substance to a reference substance (i.e., 1,4-dichlorobenzene). It was recognised that current ecotoxicity LCIA methods often produce a probably incorrect emphasis on the impact of metals (Ligthart et al. 2004). Thus, a first step in improving characterisation factors for zinc was to evaluate and update the derivation of the PNEC value for LCIA and the underlying ecotoxicological data.

\subsection{Implementation of bioavailability and essentiality}

Another way to improve the characterisation factors of essential metals is by correcting for bioavailability and essentiality (Ligthart et al. 2004). One of the main issues in the LCA of metals is the fact that currently the total load of zinc to the environment is considered bioavailable. In reality, however, a substantial part of the emitted zinc load is not available for biological uptake. Furthermore, the LCA approach follows the 'less is better' principle; which is not true for essential metals like zinc.

In the CML 2000 baseline method zinc has characterisation factors specific for each compartment (air, soil and water). The aquatic and terrestrial ecotoxicity impact categories have specific characterisation factors for ocean water and unspecified water. The proposed improvement is relevant for these compartment-specific characterisation factors.

\section{Materials and methods}

2.1 Methods to improve characterisation factor of metals

\subsubsection{Evaluation and update of current effect values}

for zinc

The derivation of the ecotoxicological effect factor for LCA was evaluated and subsequently updated. The update was based on the risk assessment report (RAR) zinc (Ministry of VROM 2008). The current data for zinc used in the CML 2000 methodology are based on unspecified sources. The 
RAR zinc is based on the most recent data, and the criteria used for the dataset were found to be stricter and better focused on the specific characteristics of an essential metal (Jongbloed et al. 2006).

Implementation of bioavailability In order to implement bioavailability in LCIA, a three-step bioavailability correction on the load of zinc was made (Fig. 1). The first step was correcting for solubility: the emission data (for the routes to water, sea, air and soil) was divided in a soluble and insoluble fraction of which only the soluble fraction was used in the LCIA. Of the dissolved fraction, only the fraction of the metal that is not adsorbed to particulate matter (or solids in soil) was considered available for biological uptake (step 2). Finally, the bioavailability fractions (i.e., the fraction of dissolved metal adsorbing to the biotic ligand) was calculated with the use of the biotic ligand model (BLM; step 3). A description of the biological, chemical, mathematical and computational aspects of the BLM can be found in Di Toro et al. (2001). For BLM, as a tool for incorporating bioavailability in environmental risk assessment of metals, we refer to Janssen et al. (2003).

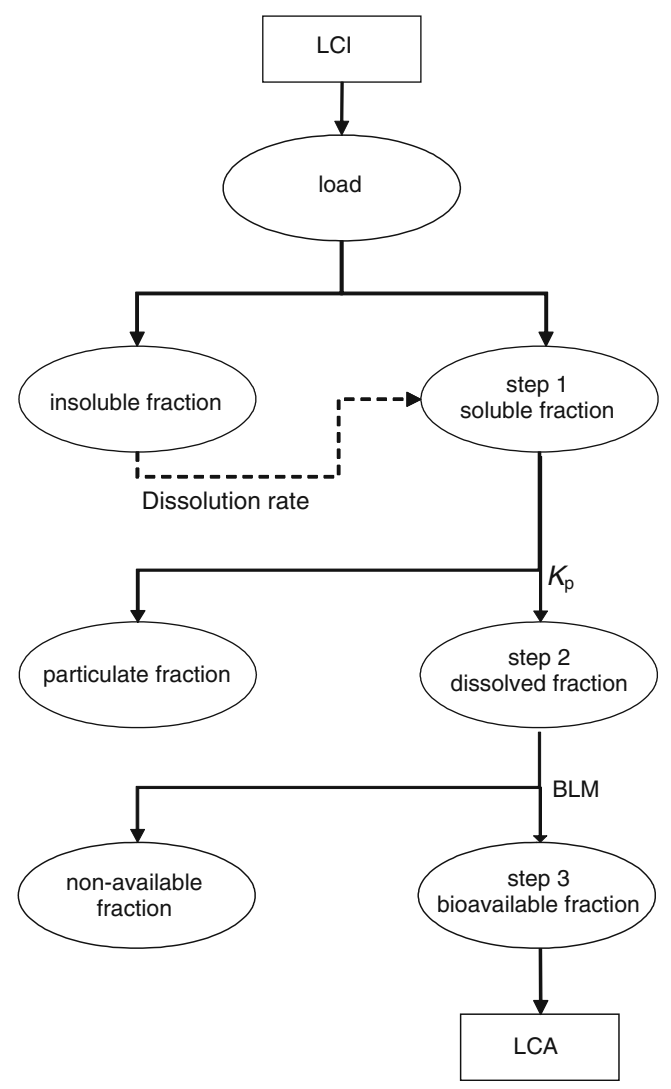

Fig. 1 Schematic overview of the potential corrections on the load of an essential metal in order to account for bioavailability in LCA
Approaching essentiality It should be noted that although a general approach was developed, correction of essentiality is not implemented in this case study. The essentiality correction covers the fact that for essential metals the paradigm of 'less is better' does not apply. This is shown in the left-hand side of Fig. 2 as the deficiency curve for essential metals. Only the emission fraction contributing to concentrations above the maximum permissible addition (MPA), in other words the point where the toxicity curve starts to have a significant effect, should be regarded as relevant for environmental impact.

\subsection{The scope of the LCA and its reference unit}

The LCA covers the full life cycle of zinc gutters and downpipes and includes the use phase. The LCA is based on company-specific data for the production of zinc gutters and downpipes for three European companies Rheinzink GmbH \& Co. KG (Germany), Building Products Unit of the UMICORE Group (Belgium, France) and Nedzink B.V. (Netherlands). The company data were averaged weighted by the relative production volumes of the three companies. The data reflect the recent (2005) Western European situation.

The units that were chosen as the reference units are: (1) the use of $1 \mathrm{~m}$ of gutter made from a 333-mm-wide and 0.7-mm-thick strip of special high-grade (SHG) zinc during 75 years, (2) the use of $1 \mathrm{~m}$ of SHG zinc downpipe with a diameter of $80 \mathrm{~mm}$ and a gauge of $0.7 \mathrm{~mm}$ during 75 years.

The period of 75 years has been chosen as this is the expected minimum service life of zinc gutters and downpipes. The width of the gutter and the diameter of the downpipe are based on a representative gutter and downpipe as used in Western Europe on a sloped roof of a house. Maintenance is included in the form of (partial) replacement and incidental painting of the system. Runoff from the gutter and downpipe materials has, of course, been included. Periodical cleaning of the gutters has not been taken into account. Table 1 shows the material use of the two product systems.

The environmental benefits of the recycling of zinc have been modelled by using the value corrected substitution for the output flows. In this approach, the economic value of the secondary material determines the amount of primary material avoided. The burden of the recycling process is included in this approach. In the 'Modelling end-of-life' section, a detailed explanation is given.

The foreground life cycle inventory (LCI) data of zinc are specific for the production of zinc products by the three European International Zinc Association members (Eggels et al. 2001), the other LCI data are from the ecoinvent database (Frischknecht and Jungbluth 2003). 


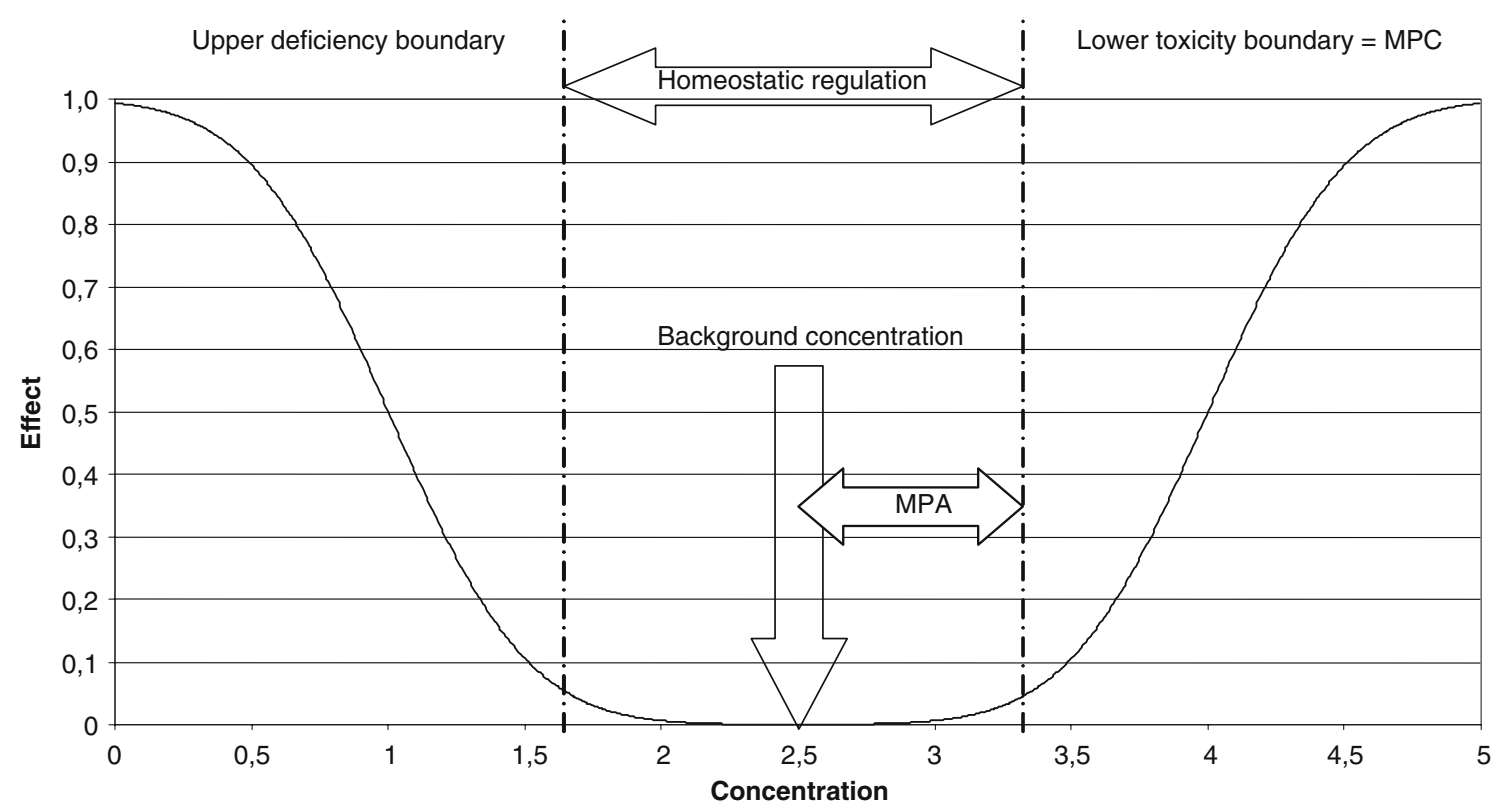

Fig. 2 Schematic overview of the deficiency and toxicity curves for essential metals, showing the deficiency and toxicity boundaries, indicating the homeostatic regulation range

\subsection{Application stage of gutter and downpipe}

During application, gutter and downpipe material may be cut off. The losses for the gutter and downpipe are estimated to be $5 \%$ of the material to be installed. The installation losses are collected for recycling.

\subsection{Use stage of gutter and downpipe}

A fraction of the zinc gutter and downpipe system is known to be painted by the owner/user of the system. We assume $5 \%$ of the gutters to be painted during their service life of 75 years. As a kind of worst case approach, it has been assumed that the painting does not reduce the runoff rate of zinc. During the service life of the system, a fraction of the installed gutters and downpipe will be (partially) replaced. We assume that this fraction is $15 \%$ (IZA 2005).

Another aspect to be considered for the use stage is the weathering of the zinc. Weathering takes places due to physical and chemical processes that change the surface of the used materials. The weathering products may become

Table 1 Quantities for the zinc gutter and downpipe needed to fulfill a single use including installation loss, replacement and overlap

\begin{tabular}{|c|c|c|c|c|}
\hline Elements & Mass & Unit & Quantity & Total $(\mathrm{kg})$ \\
\hline Gutter & 1.647 & $\mathrm{~kg} \quad \mathrm{~m}^{-1}$ & 1.23 & 2.029 \\
\hline Hangers & 0.125 & $\mathrm{~kg}$ & 2.88 & 0.359 \\
\hline Downpipe & 1.254 & $\mathrm{~kg} \mathrm{~m}^{-1}$ & 1.23 & 1.545 \\
\hline Hangers & 0.134 & $\mathrm{~kg}$ & 0.58 & 0.0771 \\
\hline
\end{tabular}

detached or dissolved; this will lead to the runoff of weathering products from the surfaces exposed to running water. The environmental impact of these weathering products has been considered. In an earlier LCA on zinc gutters and downpipes (Eggels et al. 2001), the release of zinc corrosion products (runoff) was taken at $2.5 \mathrm{~g} \mathrm{~m}^{-2}$ year ${ }^{-1}$. Due to the lowering of the $\mathrm{SO}_{2}$ concentrations in the air, which results in a reduced corrosion rate, the current runoff rate is $2.3 \mathrm{~g} \mathrm{~m}^{-2}$ year $^{-1}$ for installed zinc (van Mourik et al. 2003). This rate is a recent average calculated for the Dutch rural and urban areas. The value of $2.3 \mathrm{~g} \mathrm{~m}^{-2}$ year $^{-1}$ is at the higher end of the range of the long-term annual runoff rates of zinc (between 0.07 and $2.5 \mathrm{~g} \mathrm{Zn} \mathrm{m}^{-2}$ year $^{-1}$ ) mentioned by Bertling et al. (2006).

The corrosion of the installed zinc products leads to a loss in the amount of material available for recycling. The zinc loss for the gutter with an installed area of $0.333 \mathrm{~m}^{2}$ is $0.76 \mathrm{~g} \mathrm{year}^{-1}$. For the downpipe with an installed area of $0.251 \mathrm{~m}^{2}$, the amount annually lost is $0.58 \mathrm{~g}$.

The weathering products of the gutter and downpipe enter the environment partly directly, but the main flow enters the environment via the sewer and waste water treatment systems. For zinc, a model exists to calculate these flows for the Dutch situation. This model has been modified to be more representative for the European situation based on the situation in Germany. In Germany, $90 \%$ of the households are connected to the sewer system (Hullman 2003). The sewer system exists for $46.5 \%$ of a separate sewer system, where the relatively clean water that comes from roofs, pavements and roads is discharged to surface waters. The remaining $53.5 \%$ of the 
German sewer system consists of a combined sewer system where all waste water is led to a waste water treatment plant. In this plant, $83.5 \%$ of the zinc is separated from the waste water and ends up in the sewage sludge (Statistics Netherlands 2005). The distribution results are shown in Fig. 3.

\subsection{Modelling end-of-life}

The end-of-life stage of many products, including building products, is often highly important for the net environmental profile of the product. We therefore include this stage and have chosen to follow the avoided impact approach (see, e.g., Ekvall and Tillmann 1997). More specifically, we used the approach of value-corrected substitution developed by Werner and Richter (2000) and Werner (2005) using aluminium as an example. In this method, recycled aluminium replaces an amount of primary aluminium equal to the economic value ratio of secondary versus primary aluminium.
We will explain the application of value-corrected substitution for zinc in our case. Due to the high value of zinc scrap, $95 \%$ of the amount of zinc at the end-of-life is recycled. The recycling consists of re-melting the zinc, removing the drosses and casting of ingots. The efficiency of the process is very high: $99.25 \%$. Thus from $1 \mathrm{~kg}$ of post-consumer SHG zinc, $0.94 \mathrm{~kg}$ of secondary zinc is produced. Due to a certain loss in quality of secondary zinc compared to primary zinc. we have made an adjustment for this. The adjustment is based upon the London Metal Exchange price ratio of 0.9 for secondary zinc compared to primary zinc. A kilogram of post-consumer zinc thus avoids $0.9 \times 0.94=0.85 \mathrm{~kg}$ of primary zinc. The remaining $5 \%$ post-consumer zinc not recycled, i.e., $85 \%$ goes to a landfill and $15 \%$ to a municipal solid waste incinerator (MSWI). This reflects the current European situation.

The modelling of the avoided production of the steel hangers is based on the recycled primary content of the hangers which is $17.4 \%$. This recycled primary material avoids the production of pig iron.
Fig. 3 Distribution of zinc emissions from the zinc gutter and downpipe through the sewer system and the waste water treatment plant to soil and surface water

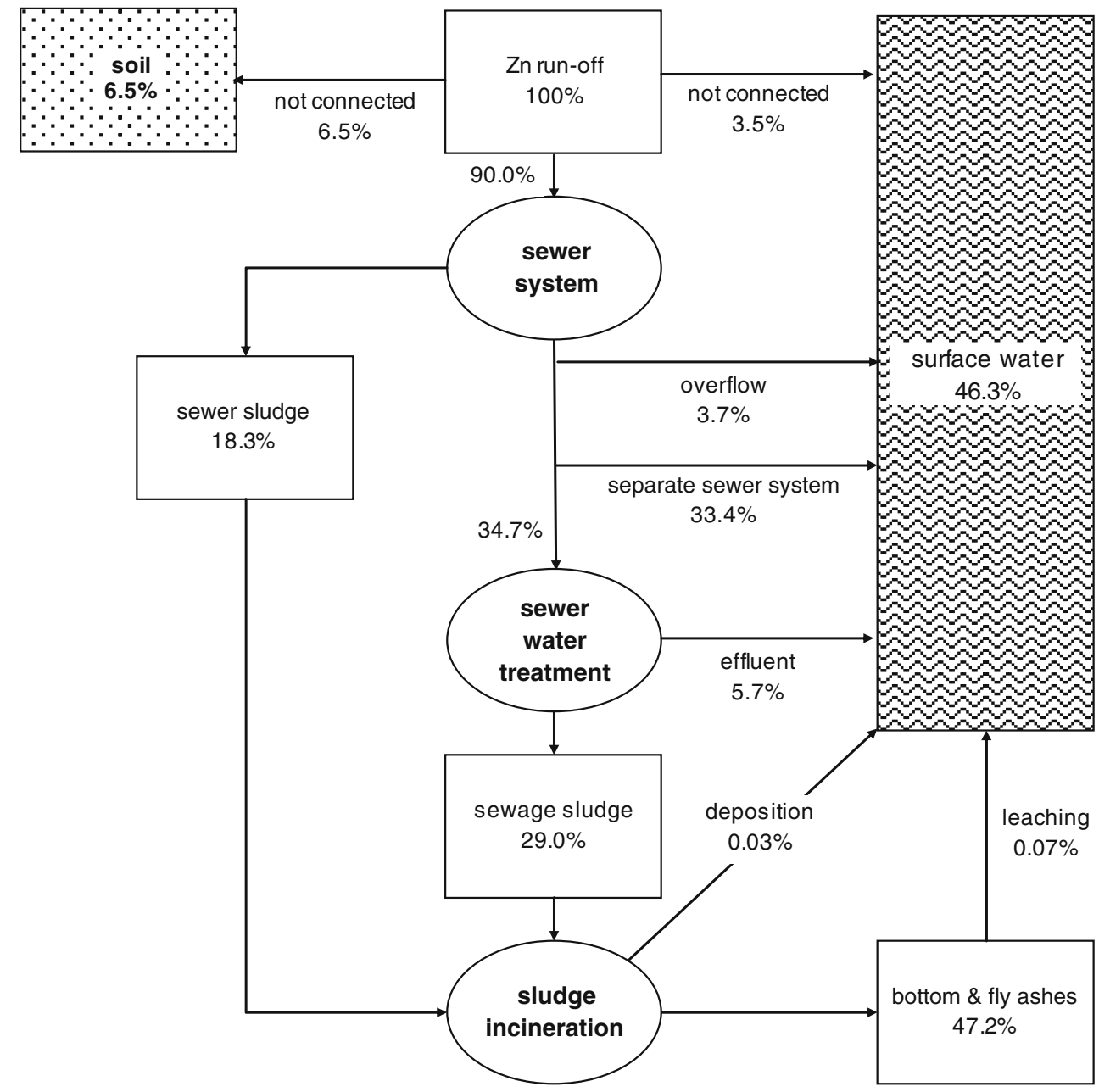




\section{Results and discussion}

\subsection{Improved characterisation factors}

\subsubsection{Evaluation and update of current effect values for zinc}

The PNEC value for the aquatic system, originally used in the CML 2000 baseline LCIA, was $6.6 \mu \mathrm{g} \mathrm{Zn} \mathrm{L}{ }^{-1}$ (Van der Zande-Guinée et al. 1999). Using the ecotoxicity data from the RAR zinc (Ministry of VROM 2008), the PNEC value was calculated at a median 5th percentile value of $15.6 \mu \mathrm{g}$ $\mathrm{Zn} \mathrm{L}{ }^{-1}$. In the RAR an additional safety factor of 2 was applied (Ministry of VROM 2008). The application of this additional safety factor (for reasons of conservatism in risk assessment) is not related to the observed ecotoxicity and would introduce additional uncertainty in setting an ecotoxicity reference value for LCA. The unadjusted value of $15.6 \mu \mathrm{g} \mathrm{Zn} \mathrm{L}{ }^{-1}$ was therefore considered to be the best basis for use in LCIA and is in this study used as the PNEC.

This study thus improved the current PNEC values in the CML 2000 baseline LCIA by using recent ecotoxicity data of the RAR zinc. It can, however, be argued whether the PNEC itself is actually a suitable figure for comparing the relative toxicity of substances as it is based on an extrapolation of the toxicity data. In many cases, the extrapolation has even a political value, as the derived PNEC should be conservative (precautionary principle). This does not necessarily reflect the differences in the toxicity of substances. In the Apeldoorn Declaration (Ligthart et al. 2004), it was therefore suggested to use a robust measure of toxicity instead of the lowest measure. Using a robust measure of toxicity instead of the lowest value means the characterisation factor should be chosen at the hazardous concentration affecting $50 \%$ of the species (HC50) level rather than on the no observed effect concentration (NOEC) level, based on the most representative not the most sensitive species. The IMPACT 2002 model has implemented this approach and used a hazard concentration affecting $50 \%$ of the species (Pennington et al. 2004). A review on different models performing ecotoxicity impact assessment of several metals showed that the relative contribution of zinc to LCIA results for certain toxicity impact categories, according to the IMPACT 2002 model (1.57\% and 5.57\% for emissions to air and water, respectively), was significantly lower compared to the uniform system for the evaluation of substances (USES)-LCA model (26.72\% and $71.02 \%$ for emissions to air and water, respectively; Gloria et al. 2006). This demonstrates that the toxicity measure has great influence on the outcome of LCIA results.

\subsubsection{Implementation of bioavailability}

Combining step 1 (correction for solubility), step 2 (correction for adsorption) and step 3 (correction for bioavailability) in the correction for bioavailability yields a correction for bioavailability as presented in Table 2 . The total correction for freshwater, marine water and soil amounts to $60 \%, 100 \%$ and $0.013 \%$, respectively. These corrections are to be multiplied by the $42 \%$ reduction in PNEC to obtain the final correction, which obtain $25 \%$, $42 \%$ and $0.006 \%$ respectively.

With the implementation of bioavailability, a conservative approach has been applied assuming 100\% of zinc emitted into the environment will dissolve. Indeed, chemical and ecotoxicological analyses of runoff water from zinc-coated materials, which is an important source for the dispersion of zinc in the environment, showed that (nearly) all zinc was present as the free $\mathrm{Zn}$ ion and was bioavailable (Heijerick et al. 2002). The bioavailability of zinc in soil however, is much lower. Dilution, organic and inorganic

Table 2 Correction for bioavailability for the aquatic freshwater, aquatic marine and soil compartments showing the application of the three-step approach

\begin{tabular}{llll}
\hline Fractions & Freshwater & Marine & Soil \\
\hline Soluble $^{\mathrm{a}}(\%)$ & - & - & - \\
Dissolved $^{\mathrm{b}}(\%)$ & 100 & 100 & 0.04 \\
BLM $^{\mathrm{c}}(\%)$ & 60 & 100 & 33 \\
Correction (\%) & 60 & 100 & 0.013 \\
\hline
\end{tabular}

a For the case study described in this paper, the soluble fraction of emissions was set to $100 \%$ (worst case) due to the lack of available data.

b For the water phase (both freshwater and marine), the CML model (as currently used in LCIA) already accounts for the adsorption to particulate matter. This fraction is not included in the calculation of the characterisation factor as only the dissolved concentration is compared with the PNEC. For the soil compartment the total soil concentrations (including the adsorbed fraction) are used for comparison with the PNEC, while only the metal dissolved in the pore water should be considered as the dissolved fraction. To express the pore water concentrations from the CML model as (dissolved) soil concentrations, a correction needs to be made of 0.0004 (the mass of metal in the pore water, divided by the total mass of soil including the pore water).

c Within the scope of the RAR, calculations were made with the BLM model in order to arrive at 'worst case' and 'generic case' bioavailability fractions (i.e., the fraction of dissolved metal adsorbing to the biotic ligand). These calculations were based on average environmental characteristics and therefore suitable to be applied in a generic LCA. The bioavailability factors for the worst case situations are 0.33 for soil and 1 for freshwater and marine water. The bioavailability factor for an average case for freshwater is 0.6. At present, the quantification of metal bioavailability is less well known for the marine environment as compared with the freshwater environment, and therefore an average case bioavailability factor for marine water will not be proposed here.

For the calculations in the present study, the generic case figure of 0.6 is used for freshwater, while the worst case factors of 0.33 and 1 are used for soil and marine environment, respectively. 
complexation and changes in speciation distribution are expected to decrease the free zinc ion concentration (and hence metal toxicity) with several orders of magnitude (Heijerick et al. 2002). The major fraction, $98-99 \%$, of the introduced total zinc concentration in runoff water emitted to soil was found to be retained within the soil (Bertling et al. 2006).

\subsubsection{Approaching essentiality}

As described in the methodology, only the emission fraction contributing to concentrations above the maximum permissible addition (MPA) should be regarded as relevant for environmental impact. However, as emissions are globally distributed, this leads to insignificant increase of environmental concentrations and therewith no metal addition exceeds the MPA. Furthermore, it should be considered that a 'continental' or even 'regional' LCA study might not provide enough detail to do make corrections for essentiality (which is actually a speciesspecific or local correction). Deficiency levels, background concentrations and MPA of metals depend on species (communities) and geographic locations and scales (local, regional, global). These complicated matters hamper a simple standard approach to correct for essentiality of metals.

\subsection{Zinc gutter and downpipe}

All life cycle stages with the exception of the installation stage of both gutter and downpipe have main impacts in one or more impact categories (Tables 3, 4 and 5, Figs. 4 and 5). The production of SHG zinc shows its main impacts (impacts of over 20\%) in six of the ten impact categories. The use phase shows main impacts for the freshwater aquatic ecotoxicity potential (FAETP) and for the photochemical ozone creation potential (POCP). For a number of categories, the main contributors to the environmental impact will be further explained. The extraction of fuels like coal, natural gas and oil comprise over $90 \%$ of the abiotic depletion potential (ADP). The extraction of zinc ore accounts for less than $5 \%$ of ADP. As the recycling of zinc at the end-of-life stage avoids the primary production of zinc, it shows a large negative impact, meaning a beneficial effect, on ADP. The ozone depletion potential (ODP) shows a large contribution of around $60 \%$ of the production of the gutter and downpipe. The use of halogenated fire suppression agents at the extraction of crude oil is the main cause for this. The emission of zinc, despite the reduced characterisation factor, is still the largest contributor to the FAETP score. The contribution of SHG zinc to the marine aquatic ecotoxicity potential (MAETP) is largely (around $60 \%$ ) caused by the emission of hydrogen fluoride that occurs when fossil fuels are incinerated. Zinc and vanadium have contributions of $10-20 \%$. The terrestrial ecotoxicity potential (TETP) shows a relative large contribution of the steel brackets especially for the zinc gutter where relatively much steel is used. It is almost fully ( $90 \%$ and over) caused by the emission of mercury during the steel production process. Sulphur oxide emissions that occur during the production of steel and tin for soldering mainly cause the acidification potential (AP). Also, the nitrogen oxides emissions, mainly occurring at the SHG zinc production, are a main contributor to AP. The latter substance is also the main cause for the eutrophication potential (EP). The release of volatile organic compounds (VOCs) from the applied paint is a main impact for the POCP.

Although the use of the heavy metal zinc as a building material has been a topic of discussion, only a few studies have been published. Eggels et al. (2001) published a report on a zinc rainwater discharge system within the scope of the Dutch environmental product declaration scheme [the Milieu Relevante Product Informatie (MRPI)]. Earlier, ATOFINA (Équipe ACV Elf Atochem 1998) published a comparative LCA on polyvinyl chloride (PVC) and zinc
Table 3 Characterised environmental profile for the zinc gutter and downpipe needed to fulfill a single use including installation loss, replacement and overlap

\begin{tabular}{llll}
\hline Impact & Unit & Zinc gutter (base) & Zinc downpipe (base) \\
\hline ADP & kg Sb eq. & $2.02 \mathrm{E}-02$ & $1.31 \mathrm{E}-02$ \\
GWP & kg CO 2 eq. & $2.94 \mathrm{E}+00$ & $1.92 \mathrm{E}+00$ \\
ODP & kg CFC-11 eq. & $3.52 \mathrm{E}-07$ & $2.07 \mathrm{E}-07$ \\
HTP & $\mathrm{kg} \mathrm{1,4-DB} \mathrm{eq.}$ & $7.45 \mathrm{E}-01$ & $3.98 \mathrm{E}-01$ \\
FAETP & $\mathrm{kg} \mathrm{1,4-DB} \mathrm{eq.}$ & $9.98 \mathrm{E}-01$ & $5.68 \mathrm{E}-01$ \\
MAETP & $\mathrm{kg} \mathrm{1,4-DB} \mathrm{eq.}$ & $1.52 \mathrm{E}+03$ & $8.73 \mathrm{E}+02$ \\
TETP & $\mathrm{kg} \mathrm{1,4-DB} \mathrm{eq.}$ & $2.28 \mathrm{E}-02$ & $6.52 \mathrm{E}-03$ \\
POCP & $\mathrm{kg} \mathrm{C}_{2} \mathrm{H}_{2}$ eq. & $9.57 \mathrm{E}-04$ & $6.03 \mathrm{E}-04$ \\
AP & $\mathrm{kg} \mathrm{SO}_{2}$ eq. & $2.56 \mathrm{E}-02$ & $1.61 \mathrm{E}-02$ \\
EP & $\mathrm{kg} \mathrm{PO}_{4}{ }^{3-}$ eq. & $2.04 \mathrm{E}-03$ & $1.08 \mathrm{E}-03$ \\
\hline
\end{tabular}


Table 4 Environmental impacts per building block of the life cycle of zinc gutter relative to the sum of impacts $\geq 0$

\begin{tabular}{|c|c|c|c|c|c|c|c|c|c|}
\hline $\begin{array}{l}\text { Impact } \\
\text { category }\end{array}$ & $\begin{array}{l}\text { (1a) } \\
\text { Production } \\
\text { of SHG zinc }\end{array}$ & $\begin{array}{l}(2 a) \\
\text { Production } \\
\text { of gutter }\end{array}$ & $\begin{array}{l}(2 \mathrm{~b}) \\
\text { Production of } \\
\text { steel brackets }\end{array}$ & $\begin{array}{l}\text { (3a) } \\
\text { Application } \\
\text { in building }\end{array}$ & $\begin{array}{l}(3 b) \\
\text { Soldering } \\
\text { zinc }\end{array}$ & $\begin{array}{l}\text { (4a) Use } \\
\text { phase }\end{array}$ & $\begin{array}{l}\text { (4b) } \\
\text { Painting }\end{array}$ & $\begin{array}{l}\text { (5a) End of } \\
\text { life gutter }\end{array}$ & $\begin{array}{l}\text { (5b) End of } \\
\text { life bracket }\end{array}$ \\
\hline ADP (\%) & 75 & 14 & 7 & 2 & 1 & 0 & 0 & -53 & 0 \\
\hline GWP (\%) & 79 & 11 & 7 & 2 & 1 & 0 & 0 & -57 & 0 \\
\hline ODP (\%) & 0 & 46 & 8 & 5 & 16 & 0 & 0 & 23 & 0 \\
\hline HTP (\%) & 23 & 30 & 35 & 3 & 4 & 2 & 0 & 2 & -1 \\
\hline FAETP $(\%)$ & 1 & 3 & 30 & 0 & 3 & 61 & 0 & 1 & 0 \\
\hline MAETP (\%) & 50 & 19 & 22 & 0 & 1 & 7 & 0 & -29 & 0 \\
\hline TETP $(\%)$ & 3 & 8 & 83 & 0 & 1 & 0 & 0 & 4 & 0 \\
\hline POCP (\%) & 19 & 6 & 15 & 3 & 5 & 0 & 52 & -10 & -1 \\
\hline $\mathrm{AP}(\%)$ & 86 & 5 & 5 & 1 & 2 & 0 & 0 & -67 & 0 \\
\hline EP (\%) & 75 & 5 & 14 & 3 & 2 & 0 & 0 & -58 & 0 \\
\hline
\end{tabular}

gutters. The main conclusion is that PVC downpipes are preferred over zinc ones. Details of the study cannot be given as it was not made available to us.

\subsection{Sensitivity analyses zinc gutter and downpipe}

The exact fraction of (partial) re-installment and repair of the gutter and downpipe during the 75-year use of the dwelling is not known. An estimate of $15 \%$ was used in the calculations of the previous results. It was shown that the production of SHG zinc and the manufacturing of the gutter and downpipe are important processes contributing to the many of the environmental impact categories. As the fraction of reinstallment/repair influences these two processes, a sensitivity analysis was made.

A case was chosen where there is a high fraction $(45 \%)$ of re-installment/repair and a case was chosen with a low fraction $(5 \%)$. It has been assumed that the fraction of re- installment of the brackets is equal to that of the zinc products. The relatively large changes in the fraction lead in the low-fraction case to a reduction of the overall impact between $91 \%$ to $97 \%$ of the base case impact for all impact categories. In the high-fraction case, the overall impact increases between $110 \%$ and 126\% (Table 6, Figs. 6 and 7). The ODP and the TETP are the most sensitive impact categories. FAETP is the least sensitive impact category, as it is determined largely by the effect of the corrosion products of zinc and less by the production of SHG zinc, the production of the two zinc products and the production of the steel brackets.

\section{Conclusions and recommendations}

With this study, the lack of data on the environmental performance of zinc gutters and downpipes has been

Table 5 Environmental impacts per building block of the life cycle of zinc downpipe relative to the sum of impacts $\geq 0$

\begin{tabular}{|c|c|c|c|c|c|c|c|c|}
\hline $\begin{array}{l}\text { Impact } \\
\text { category }\end{array}$ & $\begin{array}{l}\text { (1) } \\
\text { Production } \\
\text { of SHG Zinc }\end{array}$ & $\begin{array}{l}(2 \mathrm{a}) \\
\text { Production } \\
\text { of zinc } \\
\text { downpipe }\end{array}$ & $\begin{array}{l}\text { (2b) } \\
\text { Production } \\
\text { of steel brackets }\end{array}$ & $\begin{array}{l}\text { (3a) } \\
\text { Application } \\
\text { in building }\end{array}$ & $\begin{array}{l}\text { (4a) Use } \\
\text { phase zinc }\end{array}$ & $\begin{array}{l}\text { (4b) Painting } \\
\text { zinc }\end{array}$ & $\begin{array}{l}\text { (5a) End of life } \\
\text { stage downpipe }\end{array}$ & $\begin{array}{l}\text { (5b) End of } \\
\text { life bracket }\end{array}$ \\
\hline ADP (\%) & 81 & 15 & 2 & 2 & 0 & 0 & -57 & 0 \\
\hline GWP (\%) & 84 & 12 & 2 & 2 & 0 & 0 & -61 & 0 \\
\hline ODP (\%) & 0 & 60 & 3 & 6 & 0 & 0 & 30 & 0 \\
\hline HTP (\%) & 33 & 43 & 13 & 4 & 3 & 0 & 3 & 0 \\
\hline FAETP (\%) & 1 & 4 & 11 & 0 & 81 & 0 & 2 & 0 \\
\hline MAETP (\%) & 61 & 23 & 7 & 0 & 9 & 0 & -36 & 0 \\
\hline TETP (\%) & 7 & 22 & 59 & 1 & 0 & 1 & 10 & 0 \\
\hline POCP (\%) & 22 & 7 & 5 & 4 & 0 & 62 & -12 & 0 \\
\hline AP (\%) & 92 & 6 & 2 & 1 & 0 & 0 & -71 & 0 \\
\hline EP (\%) & 86 & 5 & 4 & 3 & 0 & 0 & -67 & 0 \\
\hline
\end{tabular}




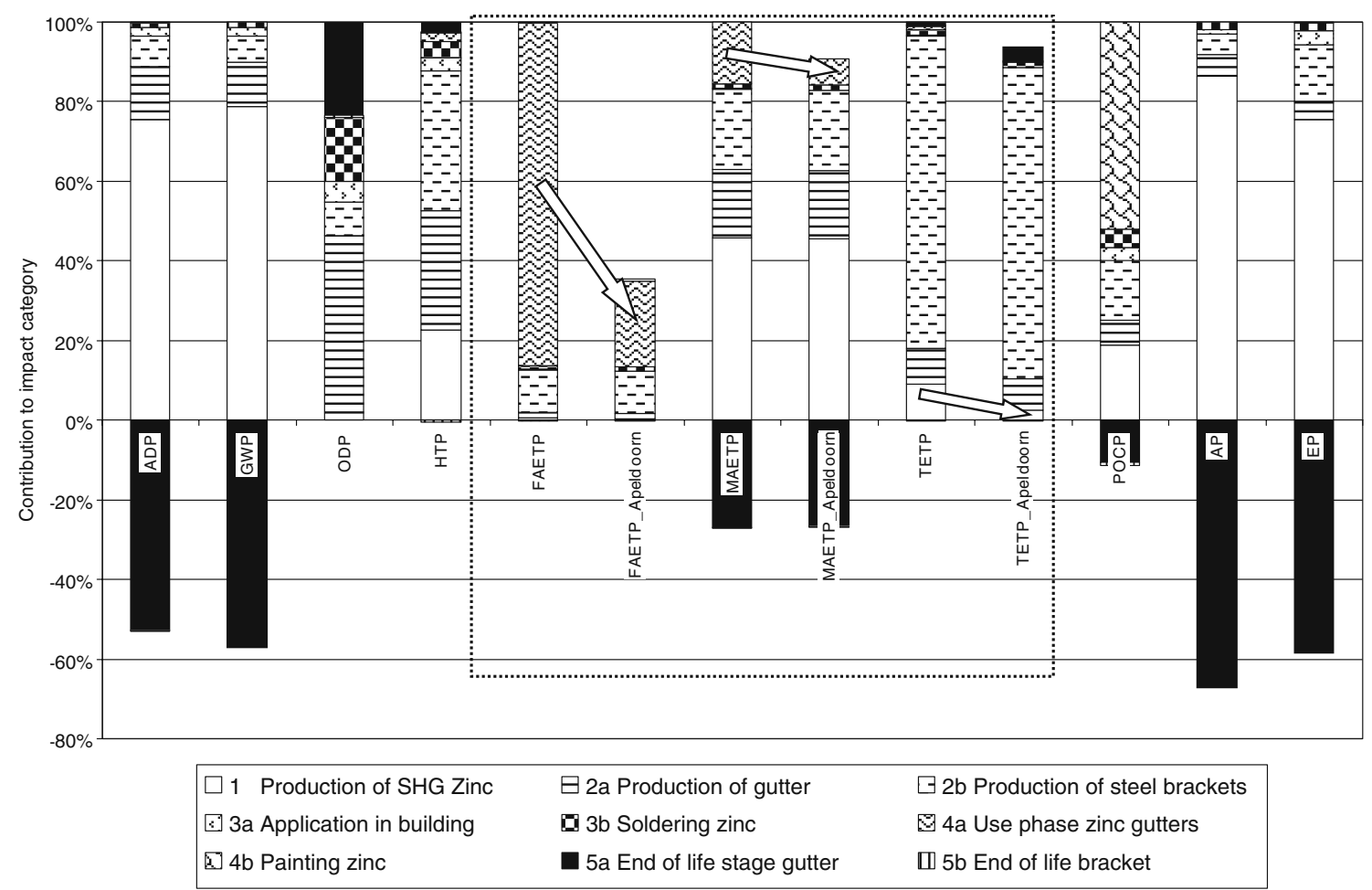

Fig. 4 Environmental profile of the life cycle stages of $1 \mathrm{~m}$ of zinc gutter, indicating the effect of the adjusted zinc characterisation factors. The bars are scaled in such a way that the positive part of each bar is $100 \%$. The impact categories effected by the adjusted characterisation factors (denoted by 'Apeldoorn') have their value relative to the original value of that impact category

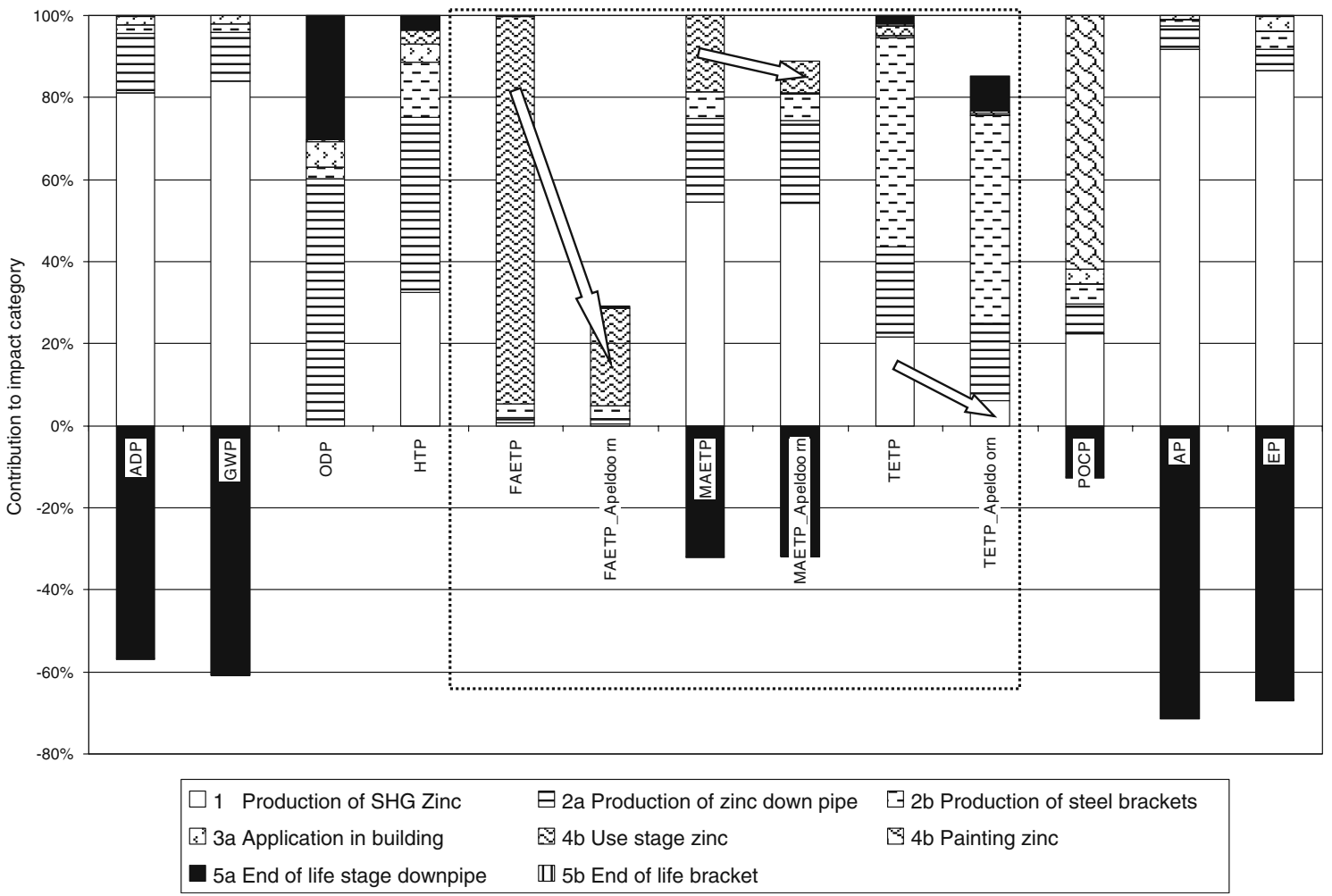

Fig. 5 Environmental profile of the life cycle stages of $1 \mathrm{~m}$ of zinc downpipe, indicating the effect of the adjusted zinc characterisation factors. The bars are scaled in such a way that the positive part of each bar is $100 \%$. The impact categories effected by the adjusted characterisation factors (denoted by 'Apeldoorn') have their value relative to the original value of that impact category 
overcome. Although a complete improvement of the characterisation factors for zinc was not achieved, we developed and demonstrated an improved LCIA method for essential metals, using zinc as a case study.

\subsection{Evaluation and update of current effect values for zinc}

The effect value for the aquatic environment was improved. A PNEC value for the aquatic environment of $15.6 \mu \mathrm{g} \mathrm{Zn} \mathrm{L}^{-1}$ has been found more up-to-date and better suitable for the purpose of LCIA, compared to the original value of $6.6 \mu \mathrm{g} \mathrm{Zn} \mathrm{L}^{-1}$.

For further improvement of LCA effect factors, it is recommended to use either the geometric mean of the effect data (when statistical extrapolation is not possible) or the HC50. Furthermore, it is recommended not to use NOEC data but to base the HC50 upon the EC50 values derived from chronic ecotoxicity tests. These data should be derived from the original publications of the data used in the $\mathrm{Zn} \mathrm{RAR}$. It is suggested to start working with a PNEC of $15.6 \mu \mathrm{g} \mathrm{Zn} \mathrm{L}^{-1}$ for surface water and a PNEC of 27,000 $\mu \mathrm{g} \mathrm{Zn} \mathrm{kg}^{-1}$ (based on microbial toxicity) for the terrestrial environment as soon as possible, making preparations for using the HC50 and chronic EC50 data on the longer term.

\subsection{Implementation of bioavailability}

It is proposed to include the bioavailability of metals in LCA in the following three steps: (1) separate soluble fraction and insoluble fraction of emitted metal, (2) separate dissolved fraction and particulate fraction in the environmental compartments and (3) separate bioavailable fraction and nonavailable fraction in the environmental compartments by BLM model calculations.
The bioavailability correction for zinc has been calculated in this study. No correction could be made for step 1 (soluble fraction) due to lack of information. Step 2 has correction for adsorption, while step 3 has correction for bioavailability. The total of steps 1-3 depends on the environmental compartment of concern. The total correction for freshwater, marine water and soil amounts to $60 \%$, $100 \%$ and $0.013 \%$, respectively. Our implementation of bioavailability showed to be consistent with other findings.

The present CML model for LCA only accounts for step 2. Therefore, it is recommended to include steps 1 and 3 to obtain total correction factors for the freshwater, marine and soil compartments. Since various physicochemical processes will alter zinc bioavailability and toxicity, it is important to correctly address these processes in LCIA. Adequate fate modelling of metals in the presence of organic matter and soil particles, such as clay, $\mathrm{Fe}$ - and Al-oxides (i.e., chemical speciation modelling), is therefore essential.

\subsection{Approaching essentiality}

The CML method accounts for background concentrations of metals; however, it does not consider essentiality of metals, and therefore the total emission contributes to environmental impact. We propose to account for essentiality by leaving out the fraction of the emission matching the concentration range below the MPA. This means that only the emission fraction contributing to concentrations above the MPA are regarded as relevant for environmental impact. The complicated issues of implementing essentiality (i.e., differentiation) should be discussed and elaborated with a group of experts in order to arrive at conclusions with a high level of acceptance.

Table 6 Comparison of high fraction $(45 \%)$ and low fraction $(5 \%)$ of re-installment/repair for the zinc gutter and downpipe relative to values for base case $(15 \%)$

\begin{tabular}{|c|c|c|c|c|}
\hline Impact category & Zinc gutter (high) & Zinc gutter (low) & Zinc downpipe (high) & Zinc downpipe (low) \\
\hline ADP (\%) & 125 & 92 & 125 & 92 \\
\hline GWP (\%) & 125 & 92 & 125 & 92 \\
\hline ODP (\%) & 126 & 91 & 126 & 91 \\
\hline HTP (\%) & 125 & 92 & 125 & 92 \\
\hline FAETP $(\%)$ & 110 & 97 & 105 & 98 \\
\hline MAETP (\%) & 123 & 92 & 122 & 93 \\
\hline TETP (\%) & 126 & 91 & 126 & 91 \\
\hline POCP (\%) & 111 & 96 & 107 & 98 \\
\hline AP (\%) & 124 & 92 & 124 & 92 \\
\hline ЕР (\%) & 125 & 92 & 124 & 92 \\
\hline
\end{tabular}




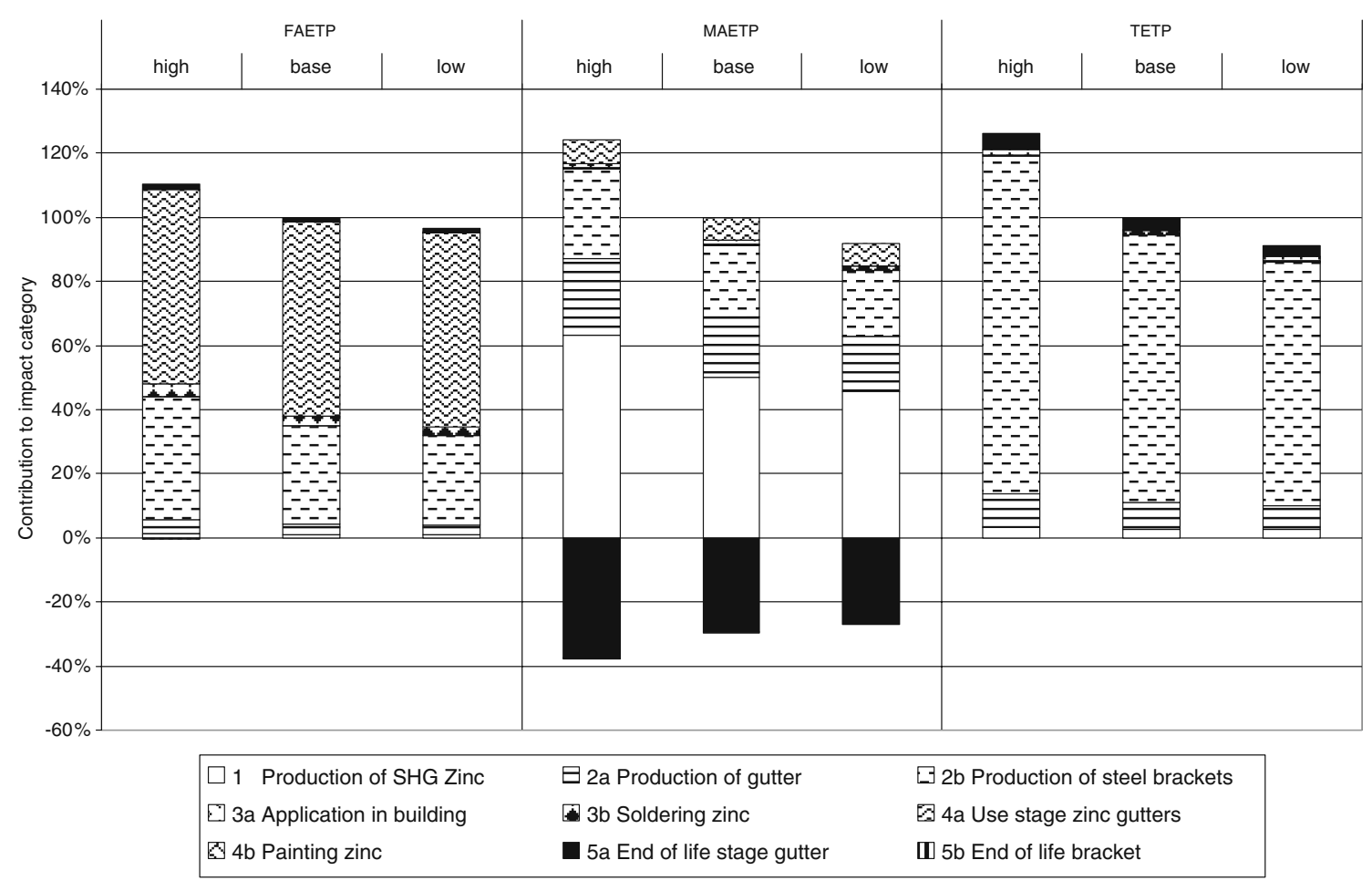

Fig. 6 Sensitivity analysis of the fraction of re-installment/repair for the zinc gutter. Base case (15\%) compared with high fraction (45\%) and low fraction (5\%). Only the ecotoxicity impact categories are shown

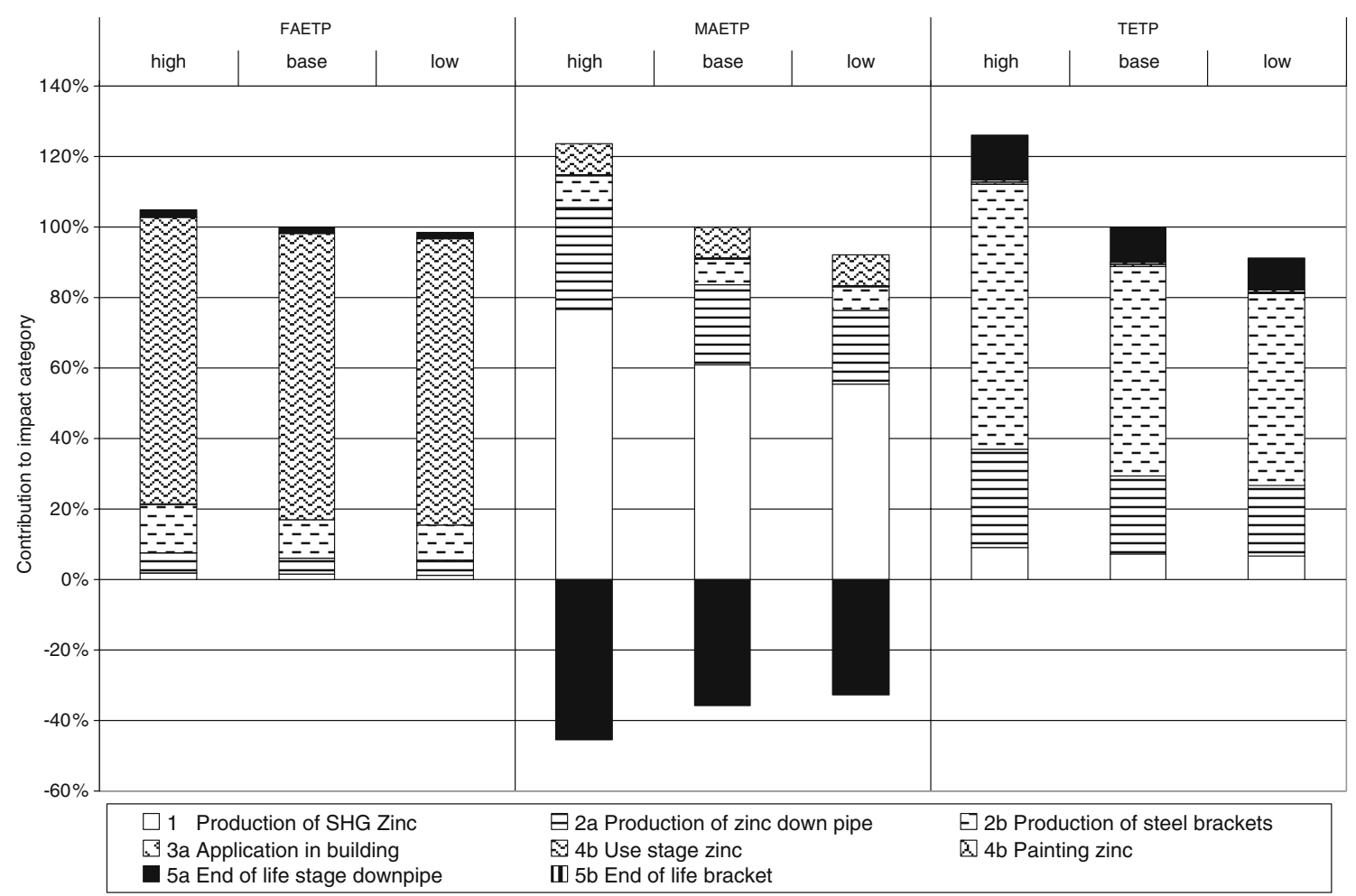

Fig. 7 Sensitivity analysis of the fraction of re-installment/repair for the zinc downpipe. Base case (15\%) compared with high fraction (45\%) and low fraction (5\%). Only the ecotoxicity impact categories are shown 
Acknowledgement The authors wish to thank the International Zinc Association for providing us with essential data for this study.

Open Access This article is distributed under the terms of the Creative Commons Attribution Noncommercial License which permits any noncommercial use, distribution, and reproduction in any medium, provided the original author(s) and source are credited.

\section{References}

Bertling S, Odnevall Wallinder I, Leygraf C, Berggren Kleja D (2006) Occurrence and fate of corrosion-induced zinc in runoff water from external structures. Sci Total Environ 367:908-923

Di Toro DM, Allen HE, Bergman HL, Meyer JS, Paquin PR, Santore RC (2001) Biotic ligand model of the acute toxicity of metals. 1. Technical basis. Environ Toxicol Chem 20:2383-2396

Eggels P, van Gijlswijk R, van der Ven B (2001) Environmental analysis of zinc gutters and down pipes; LCA, directed at MRPI. TNO report R 2001/032, January 2001

Ekvall T, Tillmann AM (1997) Open-loop recycling: criteria for allocation procedures, 2 LCA (3):155-162

Équipe ACV Elf Atochem (1998) ACV comparative de gouttières en $\mathrm{PVC}$ avec des gouttières en zinc

Frischknecht R, Jungbluth N (eds) (2003) Overview and methodology data v1.01 Ecoinvent report no. 1, Dübendorf, December 2003

Gloria TP, Russell AJ, Atherton J, Baker SR, Cook M (2006) Ecological toxicity methods and metals: an examination of two case studies. Int J Life Cycle Assess 11:26-33

Guinée J et al (2001) Life cycle assessment - an operational guide to the ISO standard, vols. I, II and III. Centrum voor Milieukunde, Universiteit Leiden, May 2001. Impact assessment based on spreadsheet version 2.2 (September 2001), http://www.leidenu niv.nl/interfac/cml/ssp/databases/cmlia/index.html

Heijerick DG, Janssen CR, Karlen C, Odnevall Wallinder I, Leygraf C (2002) Bioavailability of zinc in runoff water from roofing materials. Chemosphere 47:1073-1080

Hullman H (ed) (2003) Naturally oxidizing metal surfaces. Environmental effects of copper and zinc in building applications, Fraunhofer IRB Verlag

ISO (2006a) ISO 14040: 2006 environmental management - life cycle assessment — principles and framework
ISO (2006b) ISO 14044: 2006 environmental management — life cycle assessment - requirements and guidelines

IZA (2005) Minutes of project meeting held at initiative of zinc offices, Düsseldorf, 8 July 2005

Janssen CR, Heijerick DG, De Schamphelaere KAC, Allen HE (2003) Environmental risk assessment of metals: tools for incorporating bioavailability. Environ Int 28:793-800

Jongbloed RH, Tamis JE, Ligthart TN, Karman CC (2006) Improving LCIA for (essential) metals, using zinc as a learning case, TNO

Ligthart T, Aboussouan L, Adams W, Atherton J, Baukloh A, Chapman P, Delbeke K, Dubreuil A, Eikelboom R, Hauschild M, Heijungs R, Jolliet O, Karman C, Koning A de, Korenromp R, Kuyper J, Loos R van der, Meent D van de, Russell A, Jan Saft R, Sap G, Schönnenbeck M, Struijs J, van Tilborg W, Udo de Haes H, Verdonck F (2004) Declaration of Apeldoorn on LCIA of non-ferro metals, Apeldoorn, The Netherlands, http://www.uneptie.org/pc/ sustain/reports/lcini/DeclarationofApeldoorn final.pdf

Ministry of VROM (2008) European union risk assessment report, zinc metal, CAS no.: 7440-66-6, EINECS no: 231-175-3, European Communities. Ministries of VROM, SZW, VWS, Rapporteur, The Netherlands.

Pennington DW, Payet J, Hauschild M (2004) Aquatic ecotoxicological indicators in life-cycle assessment. Environ Toxicol Chem 23:1796-1807

Statistics Netherlands (2005) Urban waste water treatment; process data waste water treatment 2003

Van der Zande-Guinée E, Slangen R, Balk F, Huijbregts M, Kalf D, van de Plassche E (1999) Effect factors for the aquatic environment for the aquatic environment in the frame of LCA. Nijmegen, National Institute of Public Health and the Environment, Bilthoven, Interfaculty Department of Environmental Science, University of Amsterdam, Haskoning

van Mourik W, van der Mijle Meijer H, van Tilborg W, Teunissen R (2003) Emissies van bouwmaterialen (Emissions of building materials). Vaststelling van afspoelsnelheden op basis van metingen aan proefopstellingen. RIZA report 2003.027 (Dutch). RIZA Lelystad, 14 November 2003

Werner F (2005) Ambiguities in decision-oriented life cycle inventories; the role of mental models and values. Eco-efficiency in industry and science series, vol. 17. Springer, Dordrecht, Boston, London

Werner F, Richter K (2000) Economic allocation in LCA. A case study about aluminium window frames. Int J LCA 5(2):79-83 